University of Wollongong

Research Online

Faculty of Engineering - Papers (Archive)

Faculty of Engineering and Information

Sciences

$1-1-2006$

\title{
A robotic gripper based on conducting polymer actuators
}

Gursel Alici

University of Wollongong, gursel@uow.edu.au

Nam N. Huynh

University of Wollongong, nhuynh@uow.edu.au

Follow this and additional works at: https://ro.uow.edu.au/engpapers

Part of the Engineering Commons

https://ro.uow.edu.au/engpapers/1754

\section{Recommended Citation}

Alici, Gursel and Huynh, Nam N.: A robotic gripper based on conducting polymer actuators 2006, 472-477. https://ro.uow.edu.au/engpapers/1754

Research Online is the open access institutional repository for the University of Wollongong. For further information contact the UOW Library: research-pubs@uow.edu.au 


\title{
A Robotic Gripper based on Conducting Polymer Actuators
}

\author{
Gürsel ALICI and Nam N. HUYNH \\ School of Mechanical, Materials and Mechatronic Engineering \\ University of Wollongong \\ 2522, NSW, Australia \\ Email:gursel@uow.edu.au
}

\begin{abstract}
Conducting polymer actuators or as widely known as artificial muscles have many promising features such as being biocompatible and suitable to open loop control, and having high force to weight ratio. If properly engineered, they can be employed as actuators plus joints like active flexure joints articulating monolithic structures. Such structures or systems not containing any sliding and/or rolling components potentially have high positioning accuracy, which is crucial for micro/nano manipulation applications. In this paper, we employ a bending type polymer actuator to articulate two separate rigid links made up of carbon fibre such that a two-finger gripper is formed. We report on the force modeling and characterisation of the actuator and the finger, the fabrication of the fingers, and preliminary performance outcomes of the gripper. The size of each finger is $(5 \mathrm{~mm}+5 \mathrm{~mm}) \times 1 \mathrm{mmx} 0.17 \mathrm{~mm}$. The results demonstrate that conducting polymer actuators can be employed as actuators to make functional robotic devices with reasonably high force output.
\end{abstract}

Keywords - electroactive polymer actuators, system identification, robotic gripper, micromanipulation.

\section{INTRODUCTION}

It has been known for some time that polymers derived from pyrrole, aniline or thiophene can be used as Conducting Polymer (CP) actuators or artificial muscles [1]. The CP actuators based on pyrrole is known as polypyrrole (PPy) actuators. When the polymer is doped electrochemically, ions are sent inside the polymer causing volume expansion. Applying voltages as small as $1 \mathrm{~V}$ controls the volume change of the polymer in the form of expansion and contraction. The change in the volume generates a bending displacement -- the electrochemical energy is converted into mechanical energy. There has been significant amount of research on conducting polymer actuators and their use in various applications in the last decade [1-9]. Conducting polymer actuators have attracted the attention of some researchers as potential actuators and sensors for micromanipulators $[4,7,10]$. Zhou et al. [4] have reported on three types of polymer actuators including ionic conducting polymer film actuator, polyaniline actuator, and parylene thermal actuator. They have presented their fabrication and initial performance results. Smela et al. [7] have presented the development and performance outcomes of PPy and $\mathrm{Au}$ bilayer conducting polymer actuators operating in electrolyte solutions. As an extension of this study, Jager et al. [10] has fabricated a serially connected micromanipulator to pick, move, and place $100 \mu \mathrm{m}$ glass beads. It has been demonstrated that the micromanipulator is very suitable for single-cell manipulation.

This study is part of an ongoing-project on the establishment of manipulation systems such as grippers and planar mechanisms articulated with the fourth generation PPy actuators, which are fabricated at the Intelligent Polymer Research Institute at the University of Wollongong [2]. While conducting polymers have many promising features to be used as new actuators and sensors, their main drawback is low speed of response and nonlinearity due to their actuation principle, which is based on mass transfer. Possible future applications include artificial muscles, and a wide variety of sensors and actuators in biomedical systems [6] and micro/nano manipulation systems [11]. As these actuators do not contain any rolling and sliding elements, they can be suitable to micro/nano manipulation tasks, which require motion accuracy in the order of 0.05 to 0.1 micrometer (50 to 100 nanometer). In our previous studies [12-15], we reported on developing various mathematical models to predict the bending behaviour of the conducting polymer actuators and employing the models to optimize their geometry leading to high force and displacement outputs. In this study, we report on the development of a robotic gripper based on two fingers articulated with bending type polymer actuators, and model predicting the force output of the fingers. The performance results of the gripper are provided to demonstrate the suitability of the polymer actuator to make functional devices.

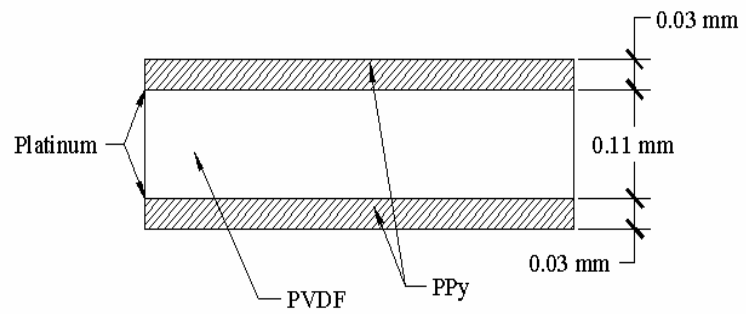

Figure 1. Cross section of the PPy-based actuator (not to scale) 


\section{CONDUCTING POLYMER ACTUATOR}

The cross section of the bending type polymer actuator considered in this study is shown in Fig. 1. The outmost two layers are polypyrrole with thicknesses of $30 \mu \mathrm{m}$. The middle layer is polyvinylidine fluoride (PVDF), an inert, non conductive, porous polymer serving as the separator of two electroactive PPy layers and reservoir for electrolyte TBA.PF 6 (tetrabutylammonium hexafluorophosphate) $0.05 \mathrm{M}$ in solvent propylene carbonate. Thin layers of platinum of 10 to $100 \AA$ are sputtered on top of PVDF to enhance the conductivity between PPy layers and electrolyte.

The structure of the actuator driving a rigid link - a finger of a robotic gripper-- is shown in Fig. 2.

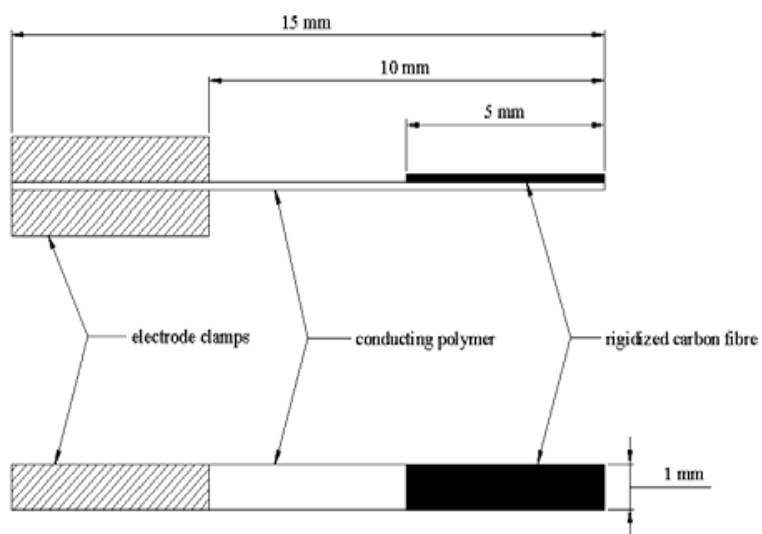

Figure 2. Structure and dimensions of the robotic finger (front view and top view).

The finger is basically a strip of PPy-based conducting polymer loaded by a thin layer of rigid carbon fibre, in which the conducting polymer works as an actuator and a joint while the carbon fibre attached on the top of the polymer serves as a rigid link for the robotic finger. The finger is typically $1 \mathrm{~mm}$ wide, $10 \mathrm{~mm}$ long $(5 \mathrm{~mm}$ for actuator part and $5 \mathrm{~mm}$ for rigid part).
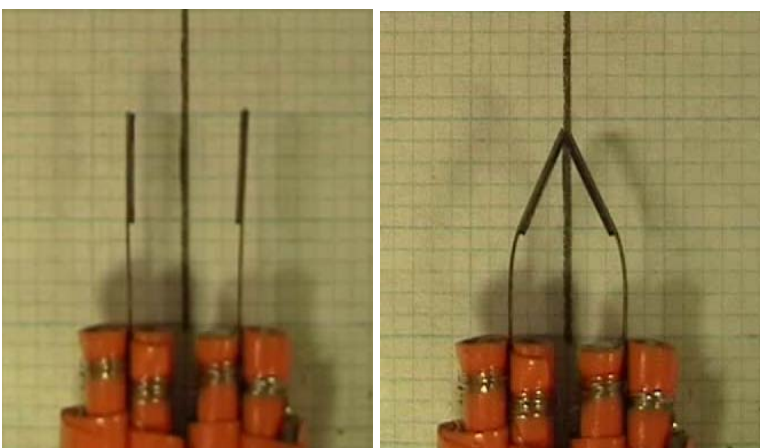

$$
\text { (a)(b) }
$$

Figure 3. Robotic gripper with the dimensions of $(5+5 \mathrm{~mm} \times 1 \mathrm{~mm} \times$ $0.17 \mathrm{~mm}$ ). (a) at the original position, (b) at the meeting point.

The fabrication process of the robotic finger is briefly outlined as follows;
(i)The sheet of conducting polymer is trimmed into strips of $1 \times 15 \mathrm{~mm}^{2}$ and carbon fibre is trimmed into pieces of $1 \times 5 \mathrm{~mm}^{2}$.

(ii)Carbon fibre pieces are cured in an oven for about 10 minutes at $100^{\circ} \mathrm{C}$. Carbon fibre should be very rigid after taken out of the oven.

(iii)Double-sided sticky tape is placed onto rigid carbon fibre pieces.

(iv)The rigid carbon fibre piece with the sticky tape on one side is then attached on the polymer strip.

The samples are replenished in tetrabutylammonium hexaflourophosphate (TBA. $\mathrm{PF}_{6}$ ) $0.05 \mathrm{M}$ electrolyte for five minutes before each test. A fabricated gripper is depicted in Fig. 3.

\section{FORCE MODEL TO PREDICT FORCE OUTPUT}

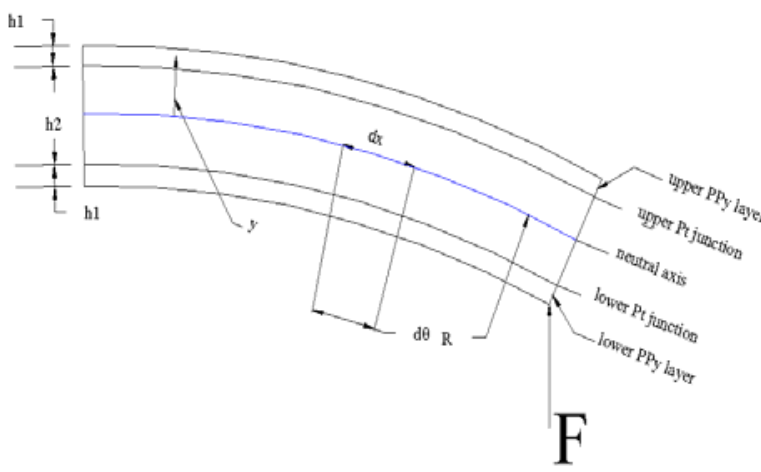

Figure 4. Actuator geometry and demonstration of parameters used in the model.

The model is developed based on the following assumptions

(i)Cross sections are plane at any position along the actuator length (pure bending).

(ii)PPy and PVDF are elastic and isotropic. The Young moduli of PPy and PVDF remain unchanged throughout the range of bending being considered.

(iii)The thickness change of PPy layers when ions move in and out during oxidation-reduction process is negligible compared to the overall thickness of the strip.

(iv)The rate of ions entering or leaving PPy layers is considered constant along the actuator length.

(v)Based on the previous assumption, the strain in PPy layers at a distance $y$ from the neutral axis due to the thickness change of PPy layer is constant throughout PPy layers and is denoted by $\alpha$. It is reported in the literature [12] that $\alpha$ is a function of the strain to charge ratio and charge density in the PPy layers.

(vi)Strain at any cross section of the actuator is symmetric about the neutral axis.

Strains in the upper PPy layer, in PVDF layer and in the lower PPy layer at a distance y from the neutral axis are, respectively.

$$
\varepsilon_{1 u}=\frac{y}{R}+\alpha \quad\left(\frac{h_{2}}{2} \leq y \leq h_{1}+\frac{h_{2}}{2}\right)
$$




$$
\begin{aligned}
& \varepsilon_{2}=\frac{y}{R}, \quad\left(-\frac{h_{2}}{2} \leq y \leq \frac{h_{2}}{2}\right) \\
& \varepsilon_{1 u}=\frac{y}{R}-\alpha, \quad\left(-h_{1}-\frac{h_{2}}{2} \leq y \leq-\frac{h_{2}}{2}\right)
\end{aligned}
$$

$\mathrm{R}$ is the radius of curvature of the neutral axis. In above equations, we assume that the bending actuator has a constant curvature along its length. Using Hooke's law, the stress in each layer is

$$
\begin{aligned}
& \sigma_{1 u}=\left(\frac{y}{R}+\alpha\right) E_{1}, \quad\left(\frac{h_{2}}{2} \leq y \leq h_{1}+\frac{h_{2}}{2}\right) \\
& \sigma_{2}=\frac{y}{R} E_{2}, \quad\left(-\frac{h_{2}}{2} \leq y \leq \frac{h_{2}}{2}\right) \\
& \sigma_{1 l}=\left(\frac{y}{R}-\alpha\right) E_{1}, \quad\left(-h_{1}-\frac{h_{2}}{2} \leq y \leq-\frac{h_{2}}{2}\right)
\end{aligned}
$$

The total moment due to the induced internal bending moment and the external force must always be zero at any cross section along the actuator when it is at a quasistatic configuration

$$
\int_{\frac{h_{2}}{2}}^{\frac{h_{2}}{2}+h_{1}} \sigma_{1 u} b y d y+\int_{-\frac{h_{2}}{2}}^{\frac{h_{2}}{2}} \sigma_{2} b y d y+\int_{-\frac{h_{2}}{2}-h_{1}}^{-\frac{h_{2}}{2}} \sigma_{1 l} b y d y-F L=0
$$

$\mathrm{F}$ is an external force acting at the actuator tip. $\mathrm{E}_{1}$ and $E_{2}$ are Young moduli of PPy and PVDF respectively, $b$ is width of the actuator, $\mathrm{L}$ is the actuator length. Substituting Eqs. (4), (5), (6) into Eq. (7) produces

$$
\begin{aligned}
& \int_{\frac{h_{2}}{2}}^{\frac{h_{2}}{2}+h_{1}}\left(\frac{y}{R}+\alpha\right) E_{1} b y d y+\int_{-\frac{h_{2}}{2}}^{\frac{h_{2}}{2}} \frac{y}{R} E_{2} b y d y+\int_{\frac{h_{2}}{2}-h_{1}}^{-\frac{h_{2}}{2}}\left(\frac{y}{R}-\alpha\right) E_{1} b y d y-F L=0 \\
& \Leftrightarrow \frac{2 E_{1} b}{R}\left[\frac{\left(\frac{\left.h_{2} / 2+h_{1}\right)^{3}}{3}-\frac{\left(h_{2} / 2\right)^{3}}{3}\right]+\alpha E_{1} b h_{1}\left(h_{1}+h_{2}\right)}{+\frac{2 E_{2} b}{R} \frac{\left(h_{2} / 2\right)^{3}}{3}-F L=0}\right.
\end{aligned}
$$

According to the actuator geometry shown in Fig. 4, the area moments of inertia of the PVDF layer and PPy layers are given by

$$
\begin{aligned}
I_{P V D F} & =\frac{b h_{2}^{3}}{12}=\frac{8 b\left(h_{2} / 2\right)^{3}}{12}=\frac{2 b\left(h_{2} / 2\right)^{3}}{3} \\
I_{P P y} & =\frac{b\left(h_{2}+2 h_{1}\right)^{3}}{12}-\frac{b h_{2}^{3}}{12}=\frac{8 b\left(h_{2} / 2+h_{1}\right)^{3}}{12}-\frac{8 b\left(h_{2} / 2\right)^{3}}{12} \\
= & \frac{2 b\left(h_{2} / 2+h_{1}\right)^{3}}{3}-\frac{2 b\left(h_{2} / 2\right)^{3}}{3}
\end{aligned}
$$

Substituting Eq. (9) and Eq. (10) into Eq. (8) results in

$$
\begin{gathered}
\frac{1}{R}\left[E_{1} I_{1}+E_{2} I_{2}\right]+\alpha E_{1} b h_{1}\left(h_{1}+h_{2}\right)-F L=0 \\
\Rightarrow \frac{1}{R} E I+\alpha E_{1} b h_{1}\left(h_{1}+h_{2}\right)-F L=0
\end{gathered}
$$

where $E I=E_{1} I_{1}+E_{2} I_{2}$ expresses the flexural rigidity for the whole actuator.

From Eq. (12), two special cases are considered.

a. Free deflection: no force is applied at the actuator tip $(F=0)$. This case determines the maximum deflection of the actuator under the effect of input voltage.

b. Zero deflection: Force is applied at the actuator tip so that vertical displacement of the tip is zero. This case identifies the maximum force that can be exerted at the tip of the actuator.

The free deflection case is applied to identify the value of $\alpha$ with the reciprocal of the radius of curvature $1 / \mathrm{R}$ being measured from experimental data. Values of $\alpha$ corresponding to different input voltages are then applied in the zero deflection case to calculate the force produced at the actuator tip.

In free deflection case, $F=0$. From Eq. (12), we have

$$
\alpha=-\frac{E I}{R E_{1} b h_{1}\left(h_{1}+h_{2}\right)}
$$

In zero deflection case, as actuators being considered are relatively small, the reciprocal of the radius of curvature $1 / \mathrm{R}$ can be approximated by zero. From Eq. (12), we have

$$
F=\frac{E_{1}^{\prime} b \alpha h_{1}\left(h_{1}+h_{2}\right)}{L}
$$

It can be inferred from Eq. (14) that the force at tip of an actuator decreases when its length increases.

The force formulation can now be applied to calculate the force created at the tip of a robotic finger. For the robotic finger structure shown in Fig. 2, the rigid part apparently does not contribute to the bending of the finger. The force model described by Eq. (14) is therefore only applied to the $5 \mathrm{~mm}$ actuator. Bending moment created by the actuator is then divided by the whole actuator length, which is $10 \mathrm{~mm}$, to approximate the force created at the finger tip.

With reference to Fig.5, the actuator length in the finger structure is denoted by a, the total length of the finger is denoted by L' and the approximated force at the finger tip is denoted by $F_{\text {finger }}$, the force created by a robotic finger can be described mathematically by Eq (15). 


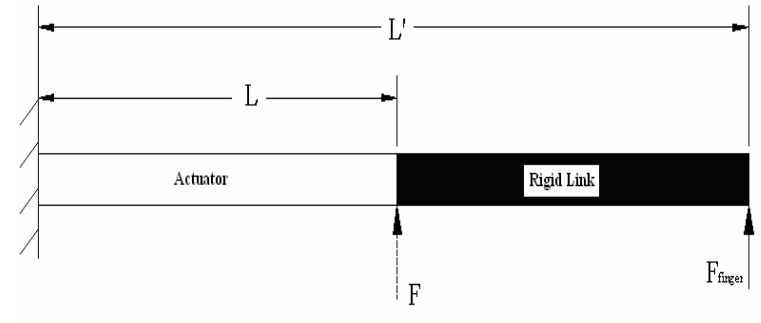

Figure 5. Demonstration of parameters in the force model for the robotic finger.

$$
F_{\text {finger }}=\frac{F a}{L^{\prime}}
$$

where $\mathrm{F}$ is calculated from Eq. (14).

\section{EXPERIMENTAL EVALUATION}

The experimental setup is shown schematically in Fig. 6.

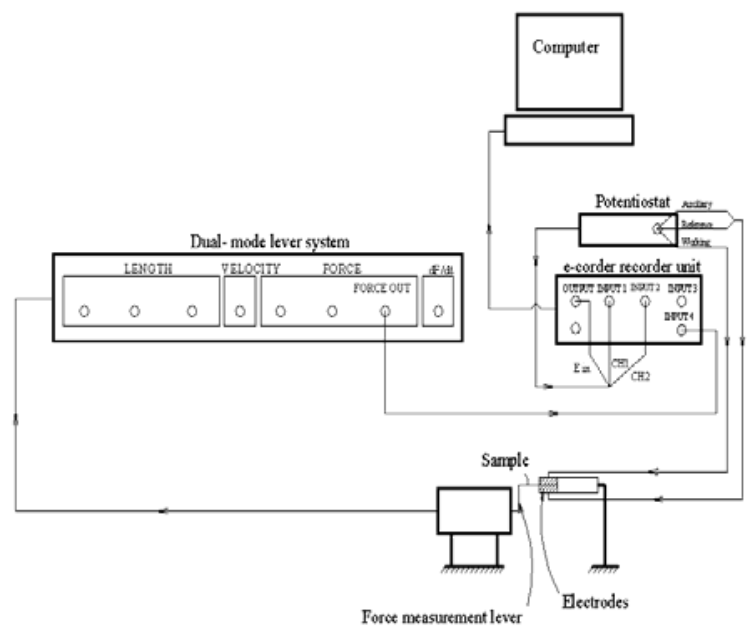

Figure 6. Schematic representation of the equipment setup.

eDAQ e-corder recorder unit is used to record, amplify, filter and, together with eDAQ Chart softwares, analyse data. eDAQ Potentiostat is a three-electrodes preamplifier. Aurora Scientific Inc. Dual-mode lever arm system, model $300 B$ is used to measure the force.

As shown by the arrows in Fig. 6, input voltage from $e D A Q$ Potentiostat is applied to the actuator sample via electrode clamps. The actuator constrained by the force sensor creates a contact force which is recorded by the ecorder recorder unit. The processed output signal from recorder unit is consecutively sent to a computer where it is displayed and analyzed using eDAQ Chart Version 5.1 for Windows. The current and voltage are sent directly from potentiostat to the e-corder recorder unit to be displayed on the computer screen. The force measurement lever is set at neutral position of the sample. The force at the tip is recorded and saved in a file together with input voltage and current. The maximum tip displacements are identified by recording movement of the strip on the grid paper using a digital video camera.
Square wave input voltages with amplitudes of $1 \mathrm{~V}$, $0.8 \mathrm{~V}, 0.6 \mathrm{~V}, 0.4 \mathrm{~V}$ and $0.2 \mathrm{~V}$ are applied. The frequency of the applied voltages is 3 pulses per minute or $0.05 \mathrm{~Hz}$. After each test, samples are neutralized by applying input voltage of $0 \mathrm{~V}$ until current passing through electrodes is zero. A typical recorded current, voltage and force data are shown in Fig. 7, as extracted from the eDAQ Chart.

The force experiments were conducted on an actuator sample with the dimensions of $5 \mathrm{~mm} \times 1 \mathrm{~mm} \times 0.17 \mathrm{~mm}$ and a robotic finger with the dimensions of $5+5 \mathrm{~mm} \times 1 \mathrm{~mm} \times$ $0.17 \mathrm{~mm}$.

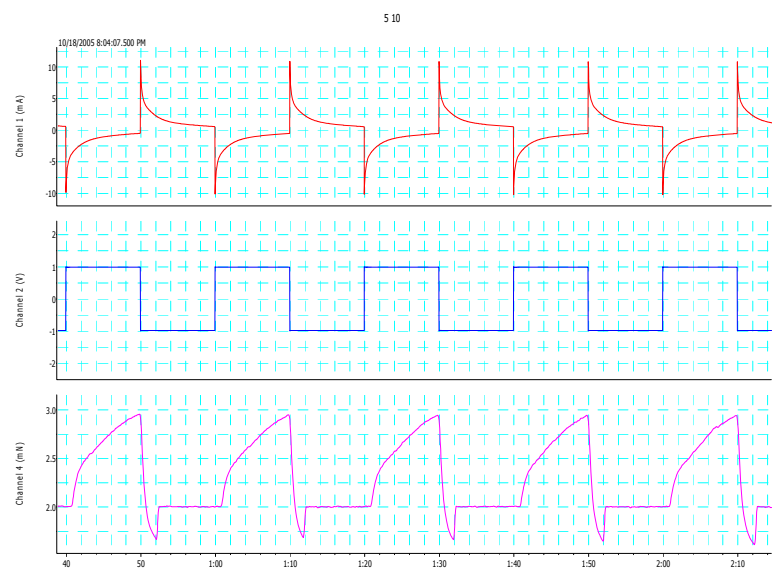

Figure 7. A typical current, voltage and force data recorded for a $5 \mathrm{~mm} \times 1 \mathrm{~mm} \times 0.17 \mathrm{~mm}$ actuator under $1 \mathrm{~V}$.

\section{EXPERIMENTAL RESULTS AND DISCUSSION}

The numerical values of the actuator parameters are

- $\quad$ PPy thickness $\mathrm{h}_{1}=0.03 \mathrm{~mm}$.

- $\quad$ PVDF thickness $\mathrm{h}_{2}=0.11 \mathrm{~mm}$.

- Width of the finger $b=1 \mathrm{~mm}$.

- Young modulus of PPy $\mathrm{E}_{1}=80 \mathrm{~N} / \mathrm{mm}^{2}$.

- Young modulus of PVDF $\mathrm{E}_{2}=440 \mathrm{~N} / \mathrm{mm}^{2}$.

The theoretical and experimental force results for the 5 $\mathrm{mm}$ actuator, and the robotic finger are shown in Fig. 8 and Fig. 9, respectively.

The results depicted in Fig. 8 and Fig. 9 show good agreement between experimental data and modeling values with input voltage up to $0.8 \mathrm{~V}$ for whole-actuator samples and up to $0.4 \mathrm{~V}$ for the robotic finger. This is mainly due to the assumption of a small and a constant curvature while the force model was developed. Therefore, it may not be accurate enough to describe the force at higher voltages.

Step response experiments were conducted to evaluate the speed of response of the actuator and the robotic finger. The results are provided in Fig. 10. A close-up of the force responses of the $5 \mathrm{~mm}$ actuator is shown in Fig. 11 , where it can be seen that there is almost no time delay in the response. Further, the higher is the input voltage, the higher is the speed of response. 

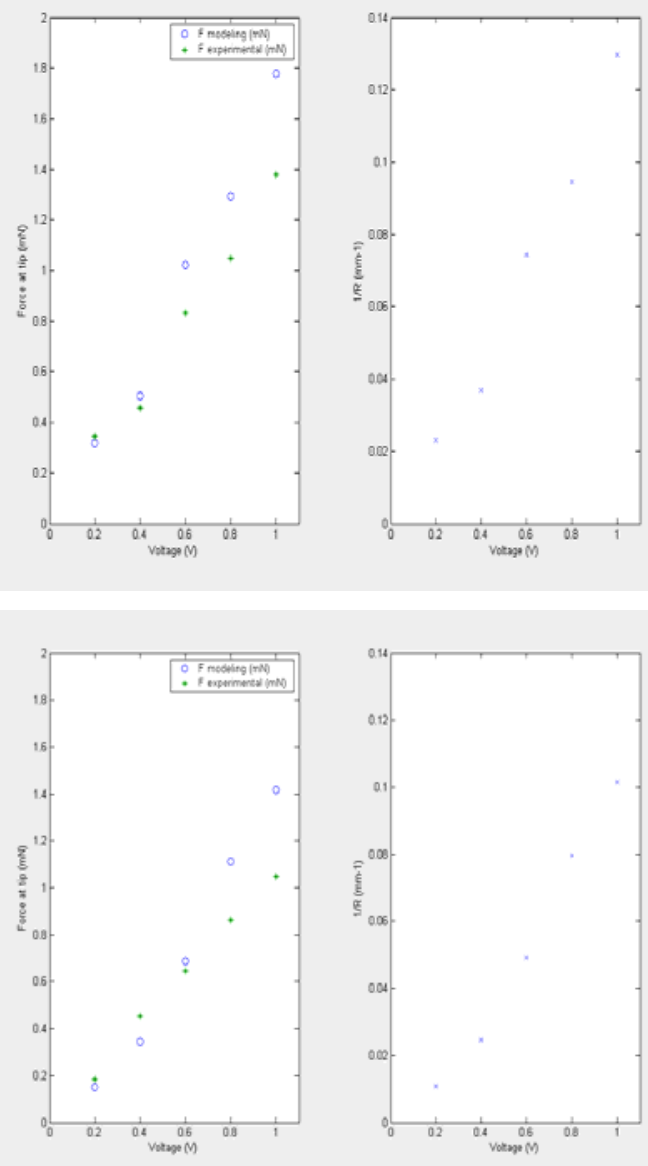

Fig. 8. Theoretical and experimental force results for two $5 \mathrm{~mm}$ actuators (the first column). The reciprocal of the corresponding radii of curvatures are shown in the second column.

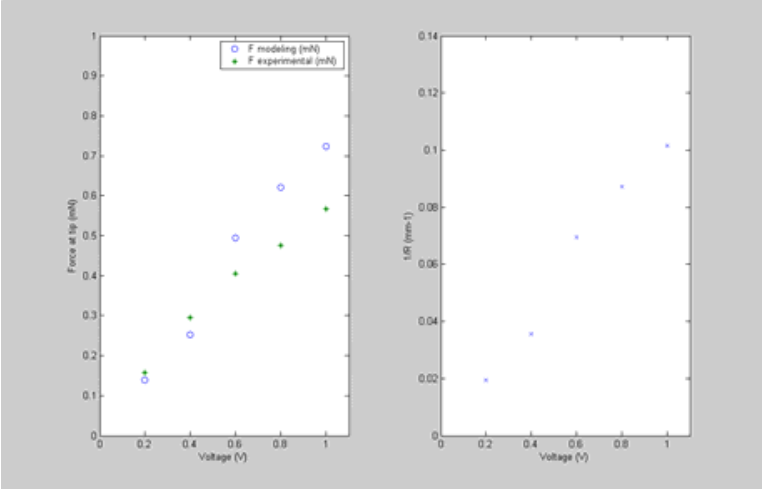

Figure 9. Theoretical and experimental force results for the robotic finger (the left plot). The inverse of the corresponding radii of curvatures are shown in the right plot.

An explanation to the inaccuracy of the force model at high input voltages is that Eq. (14) is derived from Eq. (12) with the approximation of zero bending - infinite radius of curvature $(1 / \mathrm{R}=0)$ of the actuator. However, the experiments showed that bending does exist when the actuators are in contact with the force measurement lever. Such bending is very obvious at higher input voltages and with longer actuators. As shown in Fig. 12, the $10 \mathrm{~mm}$ and $5 \mathrm{~mm}$ actuator samples bend under an input voltage of $1.0 \mathrm{~V}$. Please note that the while curvature of such bending can be negligibly small for a $5 \mathrm{~mm}$ actuator, it cannot be for a $10 \mathrm{~mm}$ actuator. The mathematical model reported in this paper needs to be refined to include bending effect in predicting the output force.

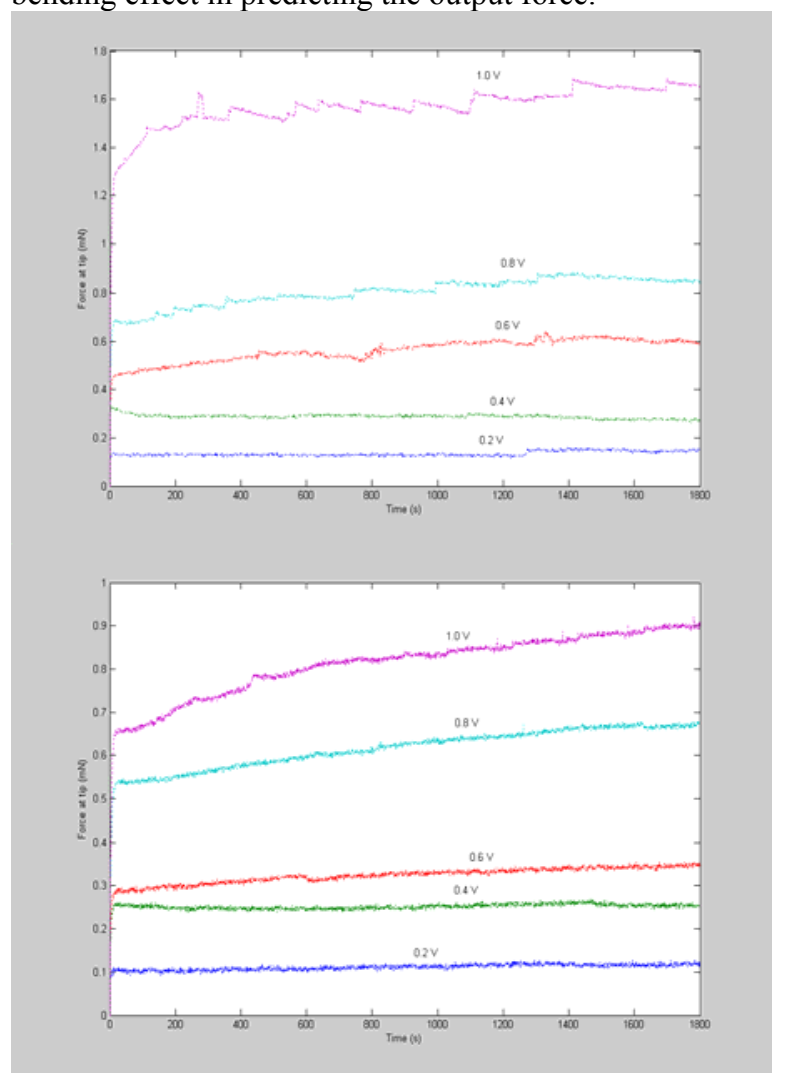

(b)

Figure 10. Force step response of of (a) $5 \mathrm{~mm}$ actuator, (b) the robotic finger under a range of input step voltages.

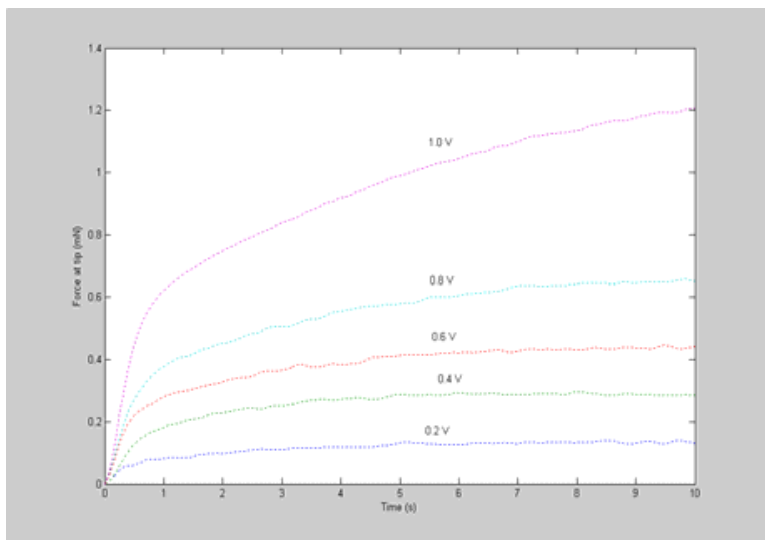

Figure 11. Force responses of the $5 \mathrm{~mm}$ actuator for the first 10 seconds under a range of input voltages.

The gripper fingers should generate equal displacement unless different displacements are applied to release objects. The gripper depicted is Fig. 3 was activated under $1 \mathrm{~V}$ and was found that both fingers meet at the middle, as shown in Fig.13, while grasping a $30 \mathrm{mg}$ object, which 
was much heavier than the total mass of the gripper. A comprehensive evaluation of the gripper performance is underway.

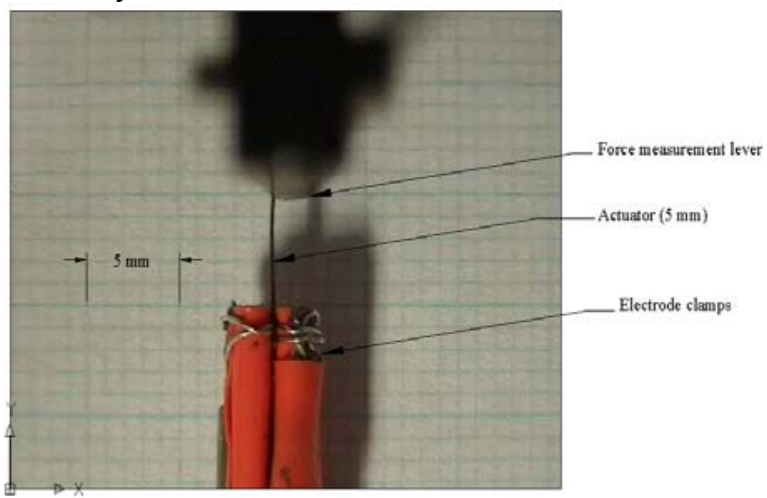

(a)

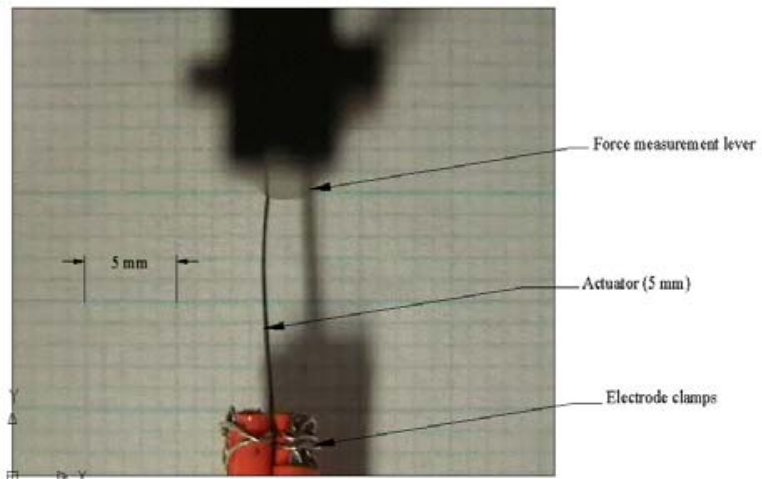

(b)

Figure 12. (a) $10 \mathrm{~mm}$ actuator and (b) $5 \mathrm{~mm}$ whole-actuator samples bending against force measurement lever.

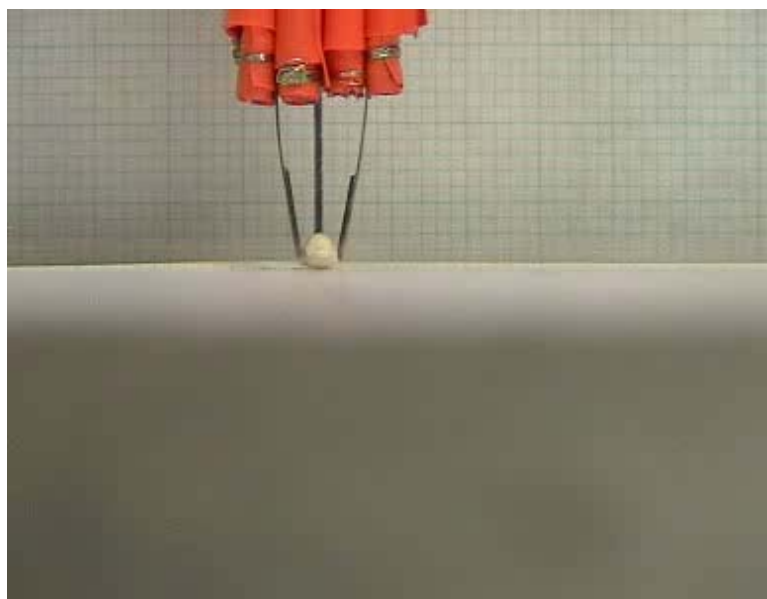

Figure 13. The robotic gripper grasping a $6 \mathrm{mg}$ object.

\section{CONCLUSIONS}

We have presented the fabrication of a two-finger gripper articulated with bending-type conducting polymers/actuators, and prediction of the force output of the actuators using an analytical model. Experimental and theoretical force results show that polymer actuators are very suitable to make functional robotic devices. Factors affecting the accuracy of the model are also discussed. The primary factor is the large deflection of the actuator, which contradicts with our fundamental modeling approach based on small deflections. The gripper was tested to successfully lift objects as much as 50 times the total weight of the polymer actuators.

\section{ACKNOWLEDGEMENTS}

This project has been partly funded by a URC Small Grant. The authors would like to thank Prof. Dr. G.M. Spinks, and Mr. Yanzhe (Richard) Wu. from the Intelligent Polymer Research Institute for providing the actuators, allowing us to use their research facilities, more importantly sharing their sterling expertise with us.

\section{REFERENCES}

1. E. W. H. Jager, E. Smela, O. Inganas, and I. Lundstrom, "Polypyrrole Microactuators", Synthetic Metals, pp. 1309 - 1310, 1999.

2. G. M. Spinks, B. Xi, D. Zhou, V. T. Truong, and G. G. Wallace, "Enhanced control and stability of polypyrrole electromechanical actuators", Synthetic Metals, Vol.140, pp. 273 - 280, 2004.

3. J. Ding, L. Liu, G. M. Spinks, D. Zhou, V. T. Truong, G. G. Wallace, and J. Gillespie, "High performance conducting polymer actuators utilising a tubular geometry and helical wire interconnects", Synthetic Metals, Vol.138, pp. 391 -- 398, 2002.

4. J. W. L. Zhou, H. Y. Chan, T. K. H. To, K. W. C. Lai, and W. L. $\mathrm{Li}$, "Polymer MEMS actuators for underwater micromanipulation", IEEE/ASME Trans. on Mechatronics, Vol.9, No.2, pp. 334 - 342, June 2004.

5. J. D. Madden, R. A. Cush, T. S. Kanigan, and I. W. Hunter, "Fast contracting polypyrrole actuators", Synthetic Metals, 113, pp. 185 $-192,2000$.

6. E. Smela, "Conjugated Polymer Actuators for Biomedical Applications", Advanced Materials, Vol.15, No.6, pp. $481-494$, March 2003.

7. E. Smela, M. Kallenbach, and Jens Holdenried, "Electrochemically Driven polypyrrole bilayers for moving and positioning bulk micromachined silicon plates", IEEE Journal of Microelectromechanical Systems, Vol.8, No.4, pp. $373-383$, December 1999.

8. Q. Pei, and O. Inganas, "Electrochemical applications of the bending beam method: 1.Mass transport and volume changes in polypyrrole during redox", Jounral of Physical Chemistry, Vol. 96, No.25, pp. 10507-10514, 1992.

9. R. H. Baughman, "Conducting polymer artificial muscles," Synthetic Metals, vol. 78, pp. 339-353, 1996.

10. E. W. H. Jager, O. Inganas, and I. Lunstrom, "Microrobots for Micrometer-size objects in Aqueous Media: Potential tools for Single Cell Manipulation”, Science, Vol.288, pp 2335 - 2338, June 30, 2000.

11. G. Alici, and B. Shirinzadeh, "Kinematics and Stiffness Analysis of a Flexure-jointed Planar Micromanipulation System for a Decoupled Compliant Motion", 2003 IEEE/RSJ International Conference on Intelligent Robots and Systems, pp. 3282 - 3287, Las Vegas, USA, October 2003.

12. G. Alici, ,B. Mui, and C. Cook, "Bending Modeling and Its Experimental Verification for Conducting Polymer Actuators Dedicated to Manipulation Applications", Sensors and Actuators, 2006. (In print)

13. G. Alici, P. Metz, and G. M. Spinks, "A Mathematical Model to Describe Bending Mechanics of Polypyrrole (PPy) Actuators", 2005 IEEE/ASME Int. Conference on Advanced Intelligent Mechatronics, pp. 1029 - 1034, Monterey, USA, July 2005.

14. G. Alici, P. Metz, and G. M. Spinks, "A Methodology towards Geometry Optimisation of High Performance Polypyrrole (PPy) Actuators", J. of Smart Materials and Structures, 2006. (In Print)

15. S. W. John, and G. Alici, "Towards micro and nano manipulation systems: behaviour of a laminated polypyrrole (PPy) actuator driving a rigid link", 2005 IEEE/ASME Int. Conf. on Advanced Intelligent Mechatronics, pp. 54 - 59, Monterey, USA, July 2005. 